\title{
The Household Health Spending and Impoverishment: Findings from the Households Survey in Shiraz, Iran
}

\author{
Khammarnia $\mathrm{M}^{1}$, Keshtkaran $\mathrm{A}^{2}$, Kavosi $\mathrm{Z}^{2}$, Hayati $\mathrm{R}^{1}$ \\ ${ }^{1}$ Student Research Committee, School of Management and Medical Information, Shiraz University \\ of Medical Sciences, Shiraz, Iran, ${ }^{2}$ Department of Health Management, School of Management \\ and Medical Information, Shiraz University of Medical Sciences, Shiraz, Iran. \\ Email: m_khammar1985@yahoo.com
}

\begin{abstract}
The present study aimed to investigate the households' impoverishment due to the healthcare costs in Shiraz in 2012. In this household's survey, 800 households were studied in Shiraz. The study sample was selected using stratified and cluster sampling in the urban and rural areas, respectively. The information was collected using the household section of the World Health Survey questionnaire. In order to determine impoverishment due to health spending, at first, the households' food-based poverty line (subsistence expenditure) was measured. Then, households' health expenditure was subtracted from their total expenditure and if the obtained value was lower than the households' food-based poverty line, the households was considered to be impoverished due to health expenditures. The collected data were entered into the SPSS (version 16) statistical software and analyzed using descriptive statistic, Chi-square test, and logistic regression in backward method. The study results showed that $7.1 \%$ of the households (CI: 0.071 \pm 0.018 ) were impoverished because of healthcare expenditures. Besides, the households in the first quintile were more likely to be faced with poverty compared to those in the other quintiles $(\mathrm{p}<0.05)$. Being covered by health insurance did not affect the protection from poverty due to health costs. Moreover, the participants living in rural areas were faced with poverty more than those living in urban areas $(\mathrm{p}<0.05)$. It seems that health expenditure can be an economic shock for household in Shiraz and through spending on health a household may fall into poverty. As insurance had no effect on impoverishment, it implies that change in health insurance plans and ways of health financing is necessary.
\end{abstract}

\section{Introduction}

Health is profoundly influenced by the factors outside the traditional realm of healthcare and poverty is one of the most important ones. ${ }^{1}$ The casual relationship between poverty and health has been recognized for decades. Researches on the effects of poverty on the health status and also inequality in health have been published. ${ }^{2,3}$ Furthermore, in several poverty reduction strategy reports of countries, poor health has been recognized as a dimension of poverty. Emphasis on the impoverishing effect of health expenditures takes its origin from the World Health Organization's (WHO) announcement of equitable contribution for financing of health costs as one of the three goals of the health systems. ${ }^{4}$

The economic burden of health services on households is measured using Catastrophic Health Expenditures (CHE) and impoverishment health spending. ${ }^{5}$ Catastrophic spending is a household's expenditure which is above a threshold percentage, while impoverishing spending pushes a household below the poverty line. This 'medical impoverishment' causes the households to be faced with very tough choices: either forgoing using healthcare services or using them and dropping the family into the poverty trap (voice of the poor). 6,7 According to national health accounts, Out Of Pocket (OOP) payment by households is the main source of healthcare financing in Iran (52-60\%); such a way that OOP expenditure has soared from $46 \%$ to $52 \%$ of the total health expenditures from 1995 to $2007 .^{8}$ This is in fact one of the major problems of health financing in Iran. This approach is considered as a highly regressive way of financing healthcare which sometimes leads to impoverishment. ${ }^{9}$ Of course, who really pays for the healthcare services surely affects the percentage of impoverished households. ${ }^{5}$ In the recent years, several reports have been published on $\mathrm{CHE}$ in Iran. Accordingly, $2.5 \%$ and $2.8 \%$ of Iranian households were faced with catastrophic expenditures in $2007^{10}$ and $2012,{ }^{11}$ respectively. 
However, a limited number of reports are available about the impoverished households showing that at least $1 \%$ of the Iranian households suffered from impoverishment in $2000 .^{12}$ The government tried to decrease OOP by putting some articles about reforming health system financing, such as universal insurance law, in the last two 5-Year National Development Plans, but it was not successful. $^{13}$

This study aimed to measure the percentage of the households falling into poverty due to health expenditures and the factors affecting impoverishment in Shiraz as the sixth metropolis in Iran. Shiraz is the capital of Fars province with 1,517,353 urban population and 215008 rural population in 2012. Similar to other parts of Iran, different health insurance schemes and health financing methods are implemented in Shiraz.

\section{Materials and Methods}

This applied cross-sectional household survey was conducted in Shiraz in 2012. The study population included all the households living in Shiraz and its suburbs. Shiraz has 387403 urban and 53757 rural households, respectively. The sample size of the present study was calculated using the following formula: ${ }^{14}$

$n=\frac{z_{1-\alpha / 2}^{2} p(1-p)}{d^{2}}$

According to regional studies in Iran, ${ }^{15,16} \mathrm{P}=10 \%$, $\mathrm{d}=3 \%, \alpha=0.05$, and $\mathrm{q}=1-\mathrm{p}$. The sample size was 800 households (703 urban and 97 rural). The study sample was selected using stratified and cluster sampling in the urban and rural areas, respectively.

The data were gathered using the household section of the "World Health Survey" developed by WHO. This section has been translated into Persian and its validity and reliability have been verified by Kavosi et al. ${ }^{16}$ One month recall period was determined for the households' total costs, consumption rates, and costs of outpatient medical care. Moreover, a year recall period was determined for the households' costs and consumption of inpatient services. Moreover, the households' expenditures were considered as an indicator of the households' purchasing power as it has been mentioned in many previous studies, as well. ${ }^{17}$

All the statistical analyses were performed using the SPSS statistical software (version 16). Descriptive statistics, Chi-square test, and logistic regression were used to analyze the data. Besides, P-values less than 0.05 were considered as statistically significant.

\section{Results}

The results showed that Among the 800 distributed questionnaires, 39 ones were excluded from the study due to the individuals' providing incomplete information or refusing to complete the questionnaires. The response rate was $95.1 \%$. The participants' mean age was 46.2 \pm 2.1 years. Moreover, the most households used the current revenues to pay the health costs $(89 \%)$. In addition, the households used their saving $(27 \%)$, borrowed from friends $(21 \%)$, and sold their assets $(7 \%)$ in order to pay the health expenditures.

Table I: Demographic variables of the households in Shiraz, 2012

\begin{tabular}{lll}
\hline Variables & dimensions & Number (\%) \\
\hline education & Below of elementary & $57(7.5 \%)$ \\
& Elementary & $107(14.1 \%)$ \\
& Middle school & $166(21.8 \%)$ \\
& High school & $255(33.5 \%)$ \\
& Academic & $176(23.1 \%)$ \\
Marriage & Single & $28(3.7 \%)$ \\
status & Married & $682(89.6 \%)$ \\
& Widowed & $41(5.4 \%)$ \\
Gender & Divorced & $10(1.3 \%)$ \\
& Male & $709(93.1 \%)$ \\
Outpatient cost in one month & $52(6.9 \%)$ \\
Physician visit cost in one month & $63(8.3 \%)$ \\
\hline
\end{tabular}

The demographic information of the participants has been demonstrated in (Table I). Almost 255 $(33.5 \%)$ of the participant had high school degree, $682(89.6 \%)$ of them were married and $511(67.1 \%)$ visit physician in a month.

Table II: Frequency of the study households regarding the independent variables of the study

\begin{tabular}{|c|c|c|}
\hline variables & dimensions & Number $(\%)$ \\
\hline \multirow{5}{*}{$\begin{array}{l}\text { Household economic } \\
\text { status }\end{array}$} & Quintile 1(the poorest) & $177(23.2 \%)$ \\
\hline & Quintile 2 & $127(16.6 \%)$ \\
\hline & Quintile 3 & $169(22.2 \%)$ \\
\hline & Quintile 4 & $146(19.2 \%)$ \\
\hline & Quintile 5 (The richest) & $142(18.3 \%)$ \\
\hline \multirow{3}{*}{$\begin{array}{l}\text { Insurance status of the } \\
\text { head of households }\end{array}$} & all & $583(76 \%)$ \\
\hline & some & $104(10 \%)$ \\
\hline & none & $74(14 \%)$ \\
\hline \multirow[t]{2}{*}{ Place of residence } & village & $644(87.3 \%)$ \\
\hline & town & $97(12.7 \%)$ \\
\hline \multicolumn{2}{|c|}{ use of hospital inpatient care } & $194(25.4 \%)$ \\
\hline \multicolumn{2}{|c|}{ the number of consuming outpatient services } & $595(78.2 \%)$ \\
\hline \multicolumn{2}{|c|}{ Consumption of dental care } & $178(23.3 \%)$ \\
\hline \multicolumn{2}{|l|}{ Cost of physician visits } & $511(67.2 \%)$ \\
\hline
\end{tabular}

According to Table II, $14 \%$ of the households were not covered by any type of health insurance. Moreover, $78.2 \%$ of the households used outpatient services, $23.3 \%$ had used dental care services in the previous month, and $25.5 \%$ had used inpatient services within the last year. 
Table III: Impoverishment caused health expenditure in the households

\begin{tabular}{lcccc}
\hline variables & dimensions & \multicolumn{2}{c}{ Household } & P Value \\
& & Poor & Impoor & \\
\hline Household & Quintile 1 & $51(28.8)$ & $126(71.2)$ & $0.001 *$ \\
economic status & Quintile 2 & $3(2.4)$ & $124(97.6)$ & \\
& Quintile 3 & $0(00)$ & $169(100)$ & \\
& Quintile 4 & $0(00)$ & $146(100)$ & \\
& Quintile 5 & $0(00)$ & $142(100)$ & \\
Insurance status & Have insurance & $49(7.8)$ & $582(92.2)$ & $0.131 *$ \\
of the head of & Have not insurance & $5(3.8)$ & $125(96.2)$ & \\
households & & & & \\
Place of & town & $30(4.5)$ & $634(95.5)$ & $0.001 *$ \\
residence & village & $24(24.7)$ & $73(75.3)$ & \\
\hline
\end{tabular}

*Significantly different at the $\mathrm{P}<0.05$ level.

Table III shows that as the economic level of the families increased the chance of being faced with poverty decreased. In addition, the households in the first quintile had a higher chance of being faced with poverty compared to those in other quintiles.

As can be seen, being covered by health insurance had no effects on protecting the households against the poverty caused health costs. The participants living in rural areas were faced with poverty more than those living in urban areas. Overall, 54 households (7.1\%) had impoverished because of healthcare expenditures in Shiraz.

Table IV: The association between the determinants and impoverishment

\begin{tabular}{lccc}
\hline variables & OR & $\begin{array}{c}\text { Confidence } \\
\text { interval }\end{array}$ & P Value \\
\hline Household economic status & 14.67 & $5.132-38.553$ & $0.001_{-}^{*}$ \\
Outpatient number & 1.258 & $1.072-1.475$ & $.049_{-}^{*}$ \\
Place of residence & .511 & $1.115-4.850$ & $.024_{-}^{*}$ \\
\hline
\end{tabular}

*Significantly different at the $\mathrm{P}<0.05$ level.

Table IV shows the results of logistic regression analysis which indicated that only three factors (household's economic status, place of living, and consumption of outpatient services) were effective in impoverishment.

\section{Discussion}

This study aimed to investigate the relationship between healthcare expenditures and impoverishment in Shiraz households. Protecting the households against CHE and poverty is among the health policy goals. There are documented evidences showing that health expenditures can impoverish the households, make them forego further treatment, sell their assets, not let the children go to school, ${ }^{6}$ substitute labor, diversify income, and even commit suicide. ${ }^{7}$ The results of the present showed that health services cost had a significant relationship with poverty $(\mathrm{P}<0.001)$ and health services expenditures caused the households to fall into poverty. In this study, $7.1 \%$ of the households had become impoverished due to health expenditures. According to Iran's fourth development program, the percentage of the households facing CHE due to health expenditures should be lower than 1, but this goal has not been achieved. ${ }^{18}$ A study conducted in Iran showed that about $2.5 \%$ of the population was at risk of catastrophic healthcare costs. For instance, $31.0 \%$ and $14.6 \%$ of the households which used inpatient care services experienced catastrophic expenditures in 2000 and 2004, respectively. ${ }^{10}$ Besides, Nekoei Moghadam believed that $2.8 \%$ of households were exposed to CHE. ${ }^{11}$ In Thailand, impoverishment increased for poor households by $84.0 \%$ in 2002 and by $71.5 \%$ in 2004 because of payments for inpatient services. ${ }^{19}$ In the same line, other study showed that $34 \%$ of the hospitalised patients had impoverished because of medical costs. ${ }^{20}$ Moreover, the households with higher inpatient expenses were more likely to borrow money and deplete their assets. ${ }^{21}$ This negative impact of health expenditures on households that can lead to impoverishment has long been ignored in the health policy agenda. Therefore, health policy makers should protect the people, particularly the poor, from impoverishment by reducing the health system's reliance on OOP payments and providing more financial protection.

The findings of the current study showed that OOP payment was the main way to supplement the heath expenditures among Shiraz households. Since OOP payment is the main source of healthcare financing in Iran $(52 \%$ to $60 \%),{ }^{8}$ it is compatible in all the cities of this country. In African countries also, OOP is the main source of providing the healthcare expenditures. ${ }^{22}$ Households especially in low income countries afford their expenditures by divesting their savings, borrowing, and selling their assets or by forgoing the treatment. ${ }^{5}$ Other studies have also supported these findings. In Vietnam, people similarly used cash reserves to meet most of the healthcare costs. ${ }^{21}$ Since OOP payment can result in impoverishment, ${ }^{23}$ it has no risk pooling benefits and consequently leads to inequity in healthcare use. Thus, the role of public prepayment schemes, such as tax or social health insurance, should be maximized and OOP payment should be minimized.

In this study, being covered by health insurance had no effects on protecting the households against poverty caused by health expenditures. Evidence has also shown that health insurance could not protect the households against CHE and poverty in low-income countries. ${ }^{24,25}$ This has also been confirmed by a study conducted in Iran. ${ }^{18}$ 
Therefore, in Iran and some developing countries, health insurance could not protect the households against poverty. Hence, as health insurance mechanism is an instrument which can protect households against illness expenditure, it seems that health policy makers should focus on redesigning health insurance systems and pay more attention to the benefit package and payment methods.

Based on the results of the present study, one of the main reasons for the households' confronting poverty was their economic status and the lowest income Quantrill was more likely to be faced with poverty caused health costs. Similar results have also been obtained in the study conducted by Nekoei in Iran. ${ }^{11}$ The findings of various studies performed in both developing and developed countries have also confirmed the effect of the households' economic status on their being faced with poverty and $\mathrm{CHE} .^{10,16}$ Poverty reduction policies which improve the level of total household welfare can be helpful, as well.

According to the results of logistic regression analysis, outpatient treatment was associated with impoverishment. In Vietnam, the households with outpatient treatment consumed less food and educational services compared to those without outpatient treatment and the most significant decrease occurred in the lowest income quartile of the population. ${ }^{27}$ Also, one study conducted in Iran indicated that the households using outpatient services were faced with catastrophic expenditures 3.5 times more than those who did not consume such services. ${ }^{15}$ The findings of the present study have been confirmed by those of the studies conducted in other countries.

Based on the results of this study, residence in urban or rural areas had different effects on being faced with poverty, which is confirmed by several other studies. ${ }^{10}$ Moreover, a study which was carried out in Iran showed that the individuals living in rural areas were more exposed to CHE compared to those in urban areas. ${ }^{11}$ This difference might be due to the villagers' lower capacity to pay and less physical and time access to health services and consequently their referring for receiving services when the disease has developed and the required services are more expensive.

In order to provide useful and constructive solutions to solve a problem, at first, it is necessary to understand the extent as well as the severity of the problem. After a while, the available solutions offered for solving the problem should be evaluated according to the position and situation of the system. Subsequently, one or some of these solutions should be used for solving the problems. ${ }^{28}$ According to the current study findings, the reasons for the households' being encountered with poverty can be summarized in three categories of high OOP payments, household's low ability to pay, and lack of protective mechanisms.

Study limitations: The limitation of the present study was a probability of over- or under-reporting of the costs as well as recall biases. However, it was attempted to minimize these problems through shortening the recall period and also reconfirming the studied cost data by randomly contacting the households who had completed the questionnaires.

Conclusion: In this study, $7.1 \%$ of the households had impoverished because of healthcare expenditures. Moreover, OOP payment was the dominant way to finance healthcare and health insurance had no protective effects. In addition, it seems that the current method of healthcare financing in Iran does not protect the households against poverty and, as a result, reformation of healthcare financing is essential in this country. Furthermore, policy makers should try to decrease the number of the households impoverished by healthcare expenditures. It seems that the policies in this regard should focus on reducing the OOP payments, promoting the households' ability to pay through public welfare mechanisms, and creating protective mechanisms, including effective insurance packages and exempting the poor from the payments. Conducting long-term prospective studies considering the behavior of the households at the time of suffering from diseases provides the policy-makers with more accurate information for making right decisions.

\section{Acknowledgements}

This article was extracted from the research project (No. 90-5887) approved by Shiraz University of Medical Sciences. The authors would like to thank all the households which kindly allocated their time for completing the questionnaires precisely and the healthcare centers administrators of Shiraz for their cooperation. Ms. A. Keivanshekouh at the Research Improvement Center of Shiraz University of Medical Sciences is also appreciated for improving the use of English in the manuscript. The research was financially supported by Shiraz University of Medical Sciences, Shiraz, Iran (SUMS).

\section{References}

1. Dahlgren G, Whitehead M. European strategies for tackling social inequities in health: Levelling up Part 2. 1th ed. Copenhagen, Denmark, World Health Organization Regional Office for Europe 2007: 2-21.

2. Goudge J GL, Russell S, Gumede T, Mills A. The household costs of health care in rural South Africa 
with free public primary care and hospital exemptions for the poor. Trop Med Int Health 2009;14(4):458-67.

3. Babu BV, Nayak AN, Dhal K, Acharya AS, Jangid PK, Mallick G. The economic loss due to treatment costs and work loss to individuals with chronic lymphatic filariasis in rural communities in Orissa, India. Acta Tropica 2002;82(1):31-8.

4. Kawabata K, Xu K, Carrin G. Preventing impoverishment through protection against catastrophic health expenditure. Bull World Health Organ 2002;80(8):612

5. Xu K, Evans DB, Kawabata K, Zeramdini R, Klavus J, Murray CJ. Household catastrophic health expenditure: a multicountry analysis. Lancet 2003;369(9378):111-7.

6. Wagstaff A, Van Doorslaer E. Catastrophic and impoverishment in paying for health care: With applications to Vietnam 1993-1998. Health Econ 2003;12(11):921-34.

7. Russell S. The economic burden of illness for households in developing countries: a review of studies focusing on malaria, tuberculosis, and human immunodeficiency virus/acquired immunodeficiency syndrome. Am J Trop Med Hyg 2004; 71(22):147-55.

8. Olyaeemanesh A, Abolhalaj M, Zanganeh M, Zakeri M, Rasidian A, Kazemian M, Ramzanian M, Beheshtian M. Iran's National Health Accounts 2008 1th ed.Tehran, Iran, Sarneveshtsazan Press,2013,p 290.

9. Devadasan N, Van Damme W, Ranson K, Van der Stuyft P. Community health insurance schemes provide partial protection against catastrophic health expenditure. BMC Health Services Research 2007;15(7):43.

10. Mehrara M FAA, Fazaeli A.A. Health Finance Equity in Iran: an Analysis of Household Survey Data (20032007) Journal of Health Administration 2010;13(40): 51-62.

11. Nekoei Moghadam M BM, Akbari Javar M, Amiresmaili M, Ganjavi S. Iranian Household Financial Protection against Catastrophic Health Care Expenditures. Iranian J Publ Health 2012;41(9):62-70.

12. Report on the health care financing policy consultative meeting. Cairo: World Health Organization, Regional office for the Eastern Mediterranean. 1th ed. Cairo, Egypt, 2006. p: 15

13. Rashidian A. Universal health coverage in Iran. Iran health. WHO-Iran Newslette 2010;6(2):1-6.

14. Chap T. LE. Introductory biostatistics, 1th ed. Hoboken, New Jersey John Wiley \& Sons, Inc Press 2003: 451-453.

15. Karami M, Najafi F, Karami Matin B. Catastrophic Health Expenditures in Kermanshah, West of Iran: Magnitude and Distribution. JRHS 2009; 9(2):36-40.

16. Kavosi Z, Rashidian A, Majdzadeh R, Pourmalek F, Hosseinpour A. Inequity in household catastrophic health care expenditure in a low-income socity of iran Health policy and planning 2012;27(7):613-23.
17. Knaul FM, Arreola-Ornelas H, Méndez-Carniado O, Bryson-Cahn C, Barofsky J, Maguire R, Miranda M, Sesma S. Evidence is good for your health system: policy reform to remedy catastrophic and impoverishing health spending in Mexico. Lancet 2006;368(9549):1828-41.

18. Health financing of Islamic Republic of Iran in fourth economic, social and cultural development plan from (2005-2009). 1th ed. Ministry of Health and Medical Education, Tehran: Iran 2010. pp: 53-69

19. Limwattananon S, Tangcharoensathien V, Prakongsai P. Catastrophic and poverty impacts of health payments: results from national household surveys in Thailand. Bulletin World Health Organ 2007;85(8): 600-6.

20. Adhikari SR, Maskay NM, Sharma BP. Paying for hospital basedcare of Kala-azar in Nepal:assessing catastrophic, impoverishment and economic consequences. Health Policy and planning 2009; 24(2): 129-39.

21. Harving ML, Rönsholt FF. The economic impact of dengue hemorrhagic fever on family level in Southern Vietnam. Danish Medical Bulletin 2007;54(2):170-72.

22. Leive $\mathrm{A}, \mathrm{Xu} \mathrm{K}$. Coping with out-of-pocket health payments: empirical evidence from 15 African countries. Bulletin of the World Health Organization 2008; 86(11): 849-56.

23. Van Doorslaer E, O'Donnell O, Rannan-Eliya RP, Somanathan A, Adhikari SR, Garg CC. Effect of payments for health care on poverty estimates in 11 countries in Asia: an analysis of household survey dataLancet. lancet 2006;368(9544):1357-64.

24. Task Force on Health Systems Research. Informed choices for attaining the Millennium Development Goals: towards an international cooperative agenda for health-systems research. Lancet 2004; 364(9438): 997 1003.

25. Ekman B. Catastrophic health payments and health insurance: Some counterintuitive evidence from one low income country. Health policy and planning 2007; 83(2):304-13.

26. Sun $\mathrm{X}$, Jackson $\mathrm{S}$, Carmichael $\mathrm{G}$, Sleigh AC. Catastrophic medical Payment and financial protection in rural china.: evidence from the new cooperate medical scheme in Shandong province health economics 2009;18(1):103-19.

27. Nguyen KT, Khuat OT, Ma S, Pham DC, Khuat GT, Ruger JP. Coping with health care expenses among poor households: evidence from a rural commune in Vietnam. Soc Sci Med 2012;74(5):724-33.

28. Ghiasvand H HM, Maleki M R. Shabaninejad H. Determinants of Catastrophic Medical Payments in Hospitals Affiliated to Iran University of Medical Sciences. Hakim Research Journal 2012;13(3):145-54. 